\title{
Not the Last Word
}

\section{Male Practice: Gender Inequality in Orthopaedic Surgery}

\author{
Joseph Bernstein MD
}

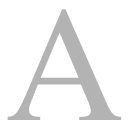

sk the typical orthopaedic surgery residency program director about the biggest problem he faces, and you are apt to hear that he is deluged with too many

Note from the Editor-in-Chief: We are pleased to present to readers of Clinical Orthopaedics and Related Research ${ }^{\mathbb{R}}$ the next Not the Last Word, a new quarterly column. The goal of this section is to explore timely and controversial issues that affect how orthopaedic surgery is taught, learned, and practiced. We welcome reader feedback on all of our columns and articles; please send your comments to eic@clinOrthop.org. The author certifies that he, or a member of his immediate family, has no funding or commercial associations (eg, consultancies, stock ownership, equity interest, patent/ licensing arrangements, etc) that might pose a conflict of interest in connection with the submitted article.

All ICMJE Conflict of Interest Forms for authors and Clinical Orthopaedics and Related Research ${ }^{\circledR}$ editors and board members are on file with the publication and can be viewed on request.

The opinions expressed are those of the writers, and do not reflect the opinion or policy of Clinical Orthopaedics and Related Research $^{\circledR}$ or the Association of Bone and Joint Surgeons ${ }^{\mathbb{R}}$.

\footnotetext{
J. Bernstein MD ( $\square)$

Department of Orthopaedic Surgery,

University of Pennsylvania,

424 Stemmler Hall, Philadelphia, PA 19104, USA

e-mail: orthodoc@uphs.upenn.edu
}

applications. Still, we need to solicit even more. Specifically, we need to convince more female students to apply_even if by so doing, life gets harder for the typical program director.

Here is the problem: The gender distribution of medical schools around the country is about 50/50; orthopedic residency programs, by contrast, are nearly $90 \%$ male [5]. To put this in context, the United States Senate, long celebrated as an "old boy's club," is only about $80 \%$ male.

Gender imbalance in orthopaedic residencies seems not to be caused by overt discrimination. Female applicants are, statistically speaking, as likely to match as their male counterparts. An elegant experiment by Scherl et al. [7] detected no anti-female bias when researchers asked reviewers to rate "chart[s] from female candidate[s that were] altered into a 'male' version." Rather, the problem is upstream: female students just are not applying to orthopaedic surgery.

There may be good reasons why female students do not seek residency positions in orthopaedics. Applying to orthopaedic surgery often entails additional study time for the United States Medical Licensing Examination ${ }^{\circledR}$ (USMLE) Step 1, the de facto residency entrance exam, as well as a few months on the road as an auditioning student. Although this investment in human capital is substantial for all applicants, the projected return on this investment is probably higher for male students. "The return from investing in [acquiring] a skill is greater when more time is spent utilizing the skill," Gary Becker said in his Nobel Lecture [2]. In general, male physicians work more hours per week than their female counterparts. In short, orthopaedic surgery positions are worth more to applicants who want (or are able) to work longer hours; and such applicants typically are men.

The financial inefficiency of on-call duties in orthopaedic surgery may also make the field unappealing to those responsible for child care-and those responsible are typically women. (That is a positive, not a normative, statement; it describes what is, not what should be.) In my experience at a community hospital, night call duties were frequent, but emergency procedures were rare. When an orthopaedic surgeon performed an operation, it was typically a simple and less-remunerative one, such as draining a septic joint. Most nights produced little or no practice revenue. An orthopaedic surgeon who arranges for frequent childcare coverage just to cover the 
contingency that her presence is needed in-house will quickly veer into deficit.

There is also the question of mentorship. Specifically, there are few female role models for women in orthopaedic surgery. A female medical student at Johns Hopkins School of Medicine, for instance, may believe that the femur is more interesting than the femoral artery, but still might choose to become a vascular surgeon, in part because the surgeon-in-chief at Hopkins is a vascular surgeon-and a female one at that. By comparison, orthopaedic surgery boasts few female chairpersons, and few professors overall. Similarly, my use of the pronoun "he" in the first paragraph of this essay was not accidental: most program directors are male as well.

Finally, there is the issue of popular perceptions. The portrayal of the stereotypical orthopaedic surgeon as "strong as an ox and just as smart" may be a myth [8] but it is a frequently touted one just the same. Image matters. Many women who enter medical school seem to think that orthopaedic surgery requires brute strength more than anything; and even with more curricular time devoted to musculoskeletal medicine than ever before [3], there is hardly an opportunity to disabuse female students of this faulty stereotype before career choices are made.
But what should really get our notice is the possibility-beyond the list of "good reasons" explaining the dearth of women in our field - of some "bad reasons." We must ask ourselves, "Is there something rotten in the state of orthopaedics?" Is there something driving women away?

I suggest that we have transitioned too slowly from the all-consuming residency and intense practice approach propounded by Halstead, (another, perhaps less-enlightened, Hopkins chief) to one more agreeable to people-male or female-whose family commitments are on par with the commitments they have made to their careers. According to the most recent American Academy of Orthopaedic Surgeons census, full-time orthopaedic surgeons on average work more than 60 hours per week; $15 \%$ of them work more than 75 ; and more than a few cross the 100-hour threshold. Granted, working long hours allows the surgeon to amortize fixed practice expenses over a wider base (and in turn earn a high hourly wage); but to me, working a "century week" routinely is an invitation to stress, burnout and despair [6].

Broadening our appeal to the entire medical school class may take effort, but the task is justified by self-interest. It is in our interest as a profession to have the best possible applicant pool, and right now too many top female students shun us. It is in our interest as a profession to have an adequately large applicant pool; and while there is a surplus today, declining payments for orthopaedic services may turn that on its head. Finally, it is in our interest as a profession to create working conditions that promote the flourishing of all members. Although that step will help make orthopaedics more welcoming to the women contemplating entering the field, it is also highly beneficial for those of us already here.

\section{Commentary}

\section{Laura Forese, MD, MPH}

Chief Operating Officer

New York Presbyterian Hospital/Weill Cornell

When I entered orthopaedic residency 25 years ago, women were few and far between. The gender imbalance did not seem so odd to me a quarter-century ago. My undergraduate degree was from a university that had recently grappled with co-education and my medical school class was nowhere near $50 \%$ women. Women were just starting to enter a number of fields and I always assumed that orthopaedic surgery would attract more and more women. But 25 years is a long time. What is the message that we send to young women when they find that they 


\section{Not the Last Word}

make up only $10 \%$ of orthopaedic surgery residents?

A review of articles from the last 10 years describing how to address the gender imbalance reveals the suggestion that we work on improving the pipeline by attracting women to orthopaedic surgery earlier in the process. That means working to address perceptions during the first few years of medical school or even college and high school. Many have also spoken to the importance of mentoring for women throughout their education and providing women with role modeling for careers in orthopaedic surgery. These are all good ideas, but it is unclear how we are measuring the effort. Whatever we are currently doing is simply not working. The data speaks for itself.

Dr. Bernstein makes some broad assumptions about why women might not be entering the field. We do not actually know why there are so few women, but his twist on the solution is definitely worth considering. Perhaps we need to change the profession for everyone as we think about how to increase the number of women. Making the profession more attractive to those who want to balance work and personal commitments, whether male or female, is a good idea.

Still, I think we are missing something quite fundamental. If we are going to make real change, we need the leadership group in orthopaedic surgery to commit to specific, measurable goals. The leaders need to speak with a clear voice regarding the desire to have women in the field and to hold themselves accountable to real metrics and real consequences. They have to acknowledge the problem, identify the remediation plans, and share the outcomes. Messaging is important: So are the results.

We never had a woman president of the American Academy of Orthopaedic Surgeons. Surely there is a woman out there who is eminently qualified. She would have many competing priorities. I am hoping that increasing the number of women in the profession would be one of them.

\section{Commentary}

\section{Dawn LaPorte, MD}

Residency Program Director

Johns Hopkins Orthopaedic Surgery training program

Gender inequality in orthopaedic surgery is real and well-documented. According to recent data from the Association of American Medical Colleges [1], orthopaedics has the lowest percentage of women residents of all specialties.

However, the cause of this imbalance remains unclear. Female medical students are actually encouraged more than discouraged to pursue orthopaedic surgery. The concerns cited by Dr. Bernstein that male physicians work more hours and women will find the field unappealing due to the financial inefficiencies of on-call duties are interesting, but I am not confident that medical students genuinely recognize or heavily weigh those issues when selecting a subspecialty.

A recent article in AAOS Now [4] also questioned why the percentage of female residents in orthopaedics was so low. The roundtable discussion found that negative perceptions discouraged women from considering orthopaedic surgery, including concerns that the culture was not welcoming to women and that it was not possible to have a family and be an orthopaedic surgeon. The importance of early exposure to musculoskeletal topics in medical school was also mentioned.

While I agree that mentors and female role models play a key part in attracting female medical students to orthopaedic surgery, I respectfully disagree with the example suggesting that a female Johns Hopkins medical student might choose vascular surgery over orthopaedics. Dr. Julie Freischlag, chair of the department of surgery at Johns Hopkins Hospital in Baltimore, $\mathrm{MD}$, is an outstanding role model and I believe she attracts women to surgery overall, not just vascular or general 
surgery, and shows them how successful women can become. Further, while Johns Hopkins Department of Orthopaedic Surgery has not had a woman as chairperson, it does have a female program director-a visible role to the medical students. Prior to my current position as residency program director, Johns Hopkins Orthopaedics had only one or two women in the 25 person residency program. We currently have seven.

Women do not necessarily need female mentors to attract them to orthopaedic surgery. Many male orthopaedic surgeons can and do serve as outstanding mentors and role models. The keys to attracting more women include making the culture more welcoming, eliminating the negative perceptions built up over many years, and recognizing the importance of work-life balance for both men and women. Increased exposure to successful and happy orthopaedic surgeons, both male and female, can help accomplish those keys.

\section{References}

1. Association of American Medical Colleges. 2012 Physician Specialty Data Book. Available at: https://members.aamc.org/eweb/upload/2012\%20 Physician\%20Specialty\%20Data\%20Book.pdf.Accessed March 18, 2013.

2. Becker GS. Nobel lecture: the economic way of looking at behavior. $J$ Polit Econ. 1993;101:385-409.

3. Bernstein J, Garcia G, Guevara J, Mitchell G. Progress report: the prevalence of required medical school instruction in musculoskeletal medicine at decade's end. Clin Orthop Relat Res. 2011;469:895-897.

4. Mason BS, Parker S, Phillips D, Vetter CS, Templeton KJ, O'Connor MI, Sabesan VJ, Shields NN. Stepping to the front: women in orthopaedic leadership. Available at: http://www.aaos.org/news/aaosnow/ mar13/clinical1.asp. Accessed March 18, 2013.

5. Nguyen L, Amin N, Vail T, Pietrobon R, Shah A. Editorial: a paucity of women among residents, faculty, and chairpersons in orthopaedic surgery. Clin Orthop Relat Res. 2010;468: 1746-1748.

6. Sargent MC, Sotile W, Sotile MO, Rubash H, Vezeridis PS, Harmon L, Barrack RL. Managing stress in the orthopaedic family: avoiding burnout, achieving resilience. J Bone Joint Surg Am. 2011;93:e40.

7. Scherl SA, Lively N, Simon MA. Initial review of electronic residency application service charts by orthopaedic residency faculty members. Does applicant gender matter? J Bone Joint Surg Am. 2001;83:65-70.

8. Subramanian $\mathrm{P}$, Kantharuban $\mathrm{S}$, Subramanian V, Willis-Owen SA, Willis-Owen CA. Orthopaedic surgeons: as strong as an ox and almost twice as clever? multicentre prospective comparative study. BMJ. 2011; 343. 